\title{
Repositioning the Learning-Disabled Performing Arts Student as Critical Facilitator
}

\author{
Liselle Terret
}

This chapter articulates and problematizes the position and status of the performing arts student with a learning disability ${ }^{1}$ within higher education. It will be argued that in order to make any sustained impact upon the current discriminatory structures prevailing, facilitation choices need to be carefully re-examined and critiqued by performing arts teachers so that students with learning disabilities are enabled to critically and explicitly explore the politics of their 'location' within and beyond such institutions. To highlight some of the challenges and consequences experienced by the student with a learning disability, where positions of leadership within the performing arts and training/ education are still denied, the positioning of these students, as performance maker and facilitator, will be critiqued through the application of an emancipatory research structure (Oliver, 1992) and performance ethnography (Denzin, 2003).

The chapter will provide examples of two workshops on a course that aimed to explore the poetics of disability arts and disability politics through satire, parody and solo-performance art in order to shift the position of the student with a learning disability. Parody was utilized as a performative tool: to confront the stereotyped myths projected onto people with learning disabilities within the media and society at large, to examine the power dynamics played out in educational institutions, and importantly to challenge perceptions on who can do the leading. 
These workshops are critiqued in the framework of performance ethnography as a means of politicizing the position of the learningdisabled student as subject and, crucially, as agent. Denzin discusses how performance ethnography is used to reveal 'struggle, as intervention, as breaking and remaking, as kinesis, as a sociopolitical act' (Denzin, 2003: 4). This analysis of the two workshops will be followed by an articulation of how an emancipatory research-model formed the basis of an ongoing reflexive and evaluative strategy occurring alongside the course. The emancipatory model is an approach in which the 'participants are involved in a process designed specifically to heighten political awareness and to lead to radical social change' (Walmsley and Johnson, 2003: 28).

In the vein of emancipatory research, the students, positioned as co-researchers and as co-facilitators, identified a number of questions that acted to interrogate and scrutinize the trajectory of the course, the tutor's pedagogical approaches in terms of relevancy and inclusivity, and the institution where the course is situated. A core group of seven learning-disabled students were co-opted to take on the dual role of co-researchers/facilitators as well as continuing as performing arts students on the course. Their role was to establish key questions for critiquing, evaluating and articulating the experiences, outcomes and politics of the course and so shifting the often assumed passive position of the student with learning-disabilities to one as expert and decisionmaker. It will be argued that an emancipatory research approach offers an opportunity for the power dynamic of the tutor-student relationship to shift and become more fluid. Data has taken the form of interviews, video recordings and workshop analysis in partnership and consultation with the students and tutors on the course.

Historically, learning-disabled people have been excluded from engaging in higher education, with this exclusion often being rationalized and justified as a way of protecting them from failure. The idea of exclusion based on pity re-enforces the medical model of disability where the person is seen as responsible for their own limitations and failings, rather than addressing the arguably inaccessible higher 
education system. This exclusion therefore assumes a narrow and also historically-influenced stereotyped definition of learning disability that assumes that people with learning disabilities lack the cognitive ability to engage in higher education. The contradiction is that higher education is arguably all about critiquing, responding to and challenging structuralist approaches to knowledge and dominant notions of intelligence, but by excluding people with learning disabilities in the structural processes the cycle of exclusion and lack of opportunity continues. Kafer (2013) explains how prejudice is expressed through feelings of benevolence, with Schweik (2009) saying that disability-based discrimination and prejudice are often condemned not as markers of structural inequality but of cruelty or insensitivity. This kind of rhetoric 'sidesteps the reality of social injustice, reducing it to a question of compassion and charitable feelings' (Schweik quoted in Kafer, 2013: 10). The inevitable impact of an institutionalized depoliticalization of learning disability on 'grounds of compassion and charitable feelings' is dangerously simplistic as it returns to structuralist binaries of able/disabled and normal/subnormal. This chapter will therefore argue that a performing arts course for students with learning disabilities situated within higher education needs to embed reflexive, critically facilitative and emancipatory research into its working structures in order to shift and ultimately transform the politics and power dynamics surrounding learning disability.

\section{The performance making diploma}

The Performance Making course, designed for adults with learning disabilities, was created in 2013 by Access All Areas (a theatre company for adults and young people with learning disabilities based in east London $)^{2}$ in partnership with the Royal Central School of Speech and Drama, ${ }^{3}$ and funded by the Leverhulme Trust. In 2015 the course won the Guardian University Award for Student Diversity and Widening Participation and is now entering into its third year with an intake of fifteen students. 
The course was created in response to the exclusion of adults with learning disabilities from current professional higher education performance-related training courses within the conservatoire and theatre industry. The course philosophy espouses that disability is a cultural and minority identity, a social category, and is therefore purposely aligned with Siebers (2008) who explains that the experiences faced by those labelled with learning disabilities creates an affinity of exclusion with other marginalized identities (Siebers, 2008: 4).

The course therefore draws on learning disability culture, disability arts and disability aesthetics ${ }^{4}$ and reaffirms the performer as co-creator in authoring devised solo and ensemble performances. The diploma is committed to developing and supporting new aesthetic performance forms and pedagogical practices that enable students to shift away from the current power dynamics that often still exist between student and teacher. The course focuses on devising within a post-dramatic frame, which is experimental, non-linear and often site-specific, with a focus on subverting and challenging hegemonic values and assumptions experienced by people with learning disabilities. Professional theatre companies and performance art practitioners who have taught on the course include Mat Fraser, Katherine Araniello, Graeae Theatre, Frantic Assembly and Punchdrunk. ${ }^{5}$

Key units within the course, 'Re-Representing Me' and 'The Politics of Performance', enable students to engage in critical self-reflection as disabled artists with agency, and in their relationship to the wider society. Nick Llewellyn, director of the course, explains the importance of this critical reflection as 'strong voices emerge as the students reflect upon their positions as learning disabled members of society' (Nick Llewellyn, 24 April 2015). The unit embraces autobiography and performance art, 'encouraging the students to use any kind of aesthetic they feel drawn to, and make choices about what they want to say' (ibid.). The course is committed to integrating politics implicitly and explicitly so that students can use the performing arts to respond to the institutionalized and social prejudices they experience on a day-to-day basis. The ethos of the course is about supporting 
each student with an individual means of communicating, expressing and engaging in this world, whilst confirming, affirming and valuing their contribution to society. Every student's participation on the course is taken seriously as they engage in performance as a form of politicized expression, influenced by the notable and important (and often unacknowledged) field of disability arts. As discussed by Hargrave (2015), 'Disability arts is an arts practice that addresses the oppression of the disabled person; a mechanism for self-advocacy and self-governance; the cultural vanguard of the social model of disability; a cultural weapon to be wielded against the twin oppressions of mainstream culture and therapeutically aligned art' (2015: 27). Disability art becomes a hybrid of performance art, offering a way in for the artist with a learning disability (in this case the non-actortrained student/performer, who has not had the opportunity to gain any conventional actor training) to claim performance and performance-making in order to offer social and political comment. Performance art has always been at the core, if not the driving force, of the course as it offers a tool for the students to negotiate and explore the idea of performativity with their own individual identities as learning-disabled artists.

Before we proceed, it is important here to acknowledge the politics surrounding the power dynamics between students (with learning disabilities) and tutor. Hargraves (ibid.) refers to Kathy Boxall's articulation of this dynamic experienced by people with learning disabilities who 'always exist under the shadow of exploitation' (Sheldon et al., 2007: 228 in Hargraves, 2015: 31). This 'shadow' is often, if not always, the elephant in the room when working with people with learning disabilities and dangerously undermines opportunities for the student with a learning disability to challenge the status quo. Boxall (2007) highlights the importance of any course for people with learning disabilities having the processes of the student-tutor dynamic made transparent and scrutinized by the students themselves so as to move beyond and challenge the status quo. The next section will articulate and critique two examples of workshops that occurred within the 
course and which embraced both disability art and performance art as a tool to move beyond Boxall's 'shadow of exploitation'.

\section{Performance art}

The first workshop to be discussed was facilitated by Katherine Araniello, also known as SickBitchCrips (SBC), ${ }^{6}$ a performance and video artist who uses subversive humour to expose hypocrisy in response to disability and social awkwardness. ${ }^{7}$ The workshop ${ }^{8}$ used performing arts to re-examine the use of media and specifically television commercials in order to challenge the representation of disability in society. Araniello encouraged the students to create a type of anti-commercial that satirized the label of disability. She is interested in using performance to leave an impression, a mark on the viewer as a way of challenging narrow readings about disability. Throughout the workshop, Araniello emphasized that 'we should all be respected ... every disabled person I know is a lot smarter than a lot of people give credit for'. Araniello was interested in establishing how the students responded to how they are 'read' by the public as disabled people. She asked the students if they could recognize where types of representation or misrepresentation could be seen in the media, including films, television programmes and commercials. A number of students responded as follows:

Student A: ... Edward Scissorhand is about someone who is somewhat different from other people but he goes out into society and people are scared of him and this is about disability ... it's about an unfinished invention.

Student B: ... through my life I got bullied ... get stared at.

Katherine: That's quite negative ... that's the idea of satire, we can play (with that stare). (ibid.)

Both students related to how Edward Scissorhand is perceived by his community and the fear that is generated when he is scapegoated in 
response to his Otherness. His 'scissorhands' are used against him; he is an easy target to point the finger at and he is mythologized as dangerous due to his different physical and cultural differences when he fails to comply with expectations placed on him. Student A's response to Araniello's question demonstrates his awareness of the social construction projected upon Scissorhand and he is able to interpret this instigated public fear as 'an unfinished invention'. Student $B$ has a different response to the symbolism of Edward Scissorhand, as she shares her experiences of being bullied. Katherine responds quickly to Student B, encouraging her to shift away from the position of victimhood into one of reclamation of identity. She suggests that the student try to 'hold onto that stare you received' and to use this as an opportunity to disable the gaze that debilitated her. This session offered an important process for the students to reclaim their agency and develop critically reflective skills so as to use the performing arts to make personal and ultimately political responses and statements to these institutionalized stereotyped myths surrounding learning disability.

Katherine facilitated an exercise where the students were asked to create commercials that satirized and subverted the media's promotion and discriminatory representation of disability. One group created an advertisement for 'Together Forever Wristbands' that strapped the person with a learning disability to two (perceived) non-disabled people on either side. The students had created an advert that parodied the paranoia and fear that surrounds disability and so exposed how 'disability' is 'done' and to whom. This is reiterated by Morris (1991), who argues that people's fear of disability is socially produced as it represents something to be feared. This idea of fear is then used to justify the exclusion of the disabled 'from common humanity, treated as fundamentally different and alien ... [hiding] their fear and discomfort by turning us into objects of pity' (Morris, 1991: 192). The very act of creating these parodied commercials as part of the course content became a political act of protest in itself, where these marginalized students were given a rightful space and place to speak of their own oppression. 
The second workshop to be discussed explored autobiography, parody and live performance, and was led by Mat Fraser ${ }^{9}$ who describes himself as 'A radically different actor entertaining with his radical difference. ${ }^{10}$ Mat began his workshop ${ }^{11}$ by offering the students an insight into how he uses live performance to challenge misperceptions of disability through his own sexuality and anger: two emotions often disconnected from disability. Mat shared a video of one of his live performances with the students, which was followed by one student commenting that 'it was like taking the moment out of being disabled and so it turned the focus around' (Student C, 20 May 2014). This student could relate to Mat's work as someone frustrated at society's constant projecting of negative labels onto him as un-able. Mat contextualized the history of this exploitation and marginalization of disabled people and how this is perpetuated through a lack of opportunities for self-representation and denial of genuine citizenship. Mat asked the students to create autobiographical, live performances that challenged perceptions of learning disability within society and so repositioning the subject as agent. This process of using autobiographical performance to re-examine and politicize how disability is read in society can be viewed as a type of performance ethnography as the process of authoring, reframing and performing their stories enabled the students to use performance as a political act that revealed agency. The students created autobiographical solo performances, revealing an agency, authority and status with regard to their lived and embodied experiences. As Denzin articulates, 'the writer-as-performer is self-consciously present, morally and politically self-aware' (2003: 14-15), and so the students' actions in Mat's task became more than just 'having a voice' or a space for a moment in time. Instead, the course became potentially a vehicle that supported and nurtured these students as they exercised their rights as creative and politicized citizens. In another example, Student $\mathrm{C}$ performed his rap in response to the autobiographical performance-art task. The performance was about the constant challenge and resilience required to beat the daily experience of discrimination. 
You see me walking everywhere,

People stop and stare.

I have to calm down, find the situation in the humiliation,

I have strong determination to fight it, to get out of the intention,

It's a big dose of communication.

I'm high up in the sky, trying to reach up,

Come on, don't tear me down,

Use that to rise up.

Don't tear me down. You are a part, inside of me.

It's like fight it, fight it, fight it. Don't go crazy.

Everybody is in it together.

And then there is peace and harmony. (Student C, 25 May 2014)

In this moment, Student $\mathrm{C}$ utilizes the performing arts to express and articulate the battle he experiences every time he walks down the street. Through his authored rap he shares his survival mechanism and expresses a profound empathy towards those who oppress him, saying, 'Everybody is in it together'; he forgives, and then there is 'peace and harmony'. Mat praises this student's ability to create an upbeat yet horrifying and real story performed as a poetic dance rap. This rap impacts upon its audience and, as Denzin notes, the 'performance authorises itself ... through its ability to evoke and invoke shared emotional experience and understanding between performer and audience' (Denzin, 2003: 13). The immediate reaction in the workshop by the other students was powerful and inspiring, with supportive gestures and comments including, 'yes, that's it; but it's so hard to do' (25 May 2014). In contrast, another student's autobiographical performance began very differently; she presented a story of victimhood during which Mat intervened and facilitated a reframing of her experience:

Student D: My disability makes me feel uncomfortable. I have no life without being disabled. I feel left out ... my life is ruined ... cause of my disability.

[Here, the students gets upset and Mat steps in.]

Mat: You nearly had a mini-moment in that, but you took a breath 
and you carried on. That's emotional stuff; we are dealing with the heart. You delivered it, you had your moment, you breathed it off. Very professional, so funny isn't always appropriate. Now your statement, I have no life is pretty strong. You're not allowed to get emotional, we are professionals. Take a deep breath. But if I'm watching someone dancing, with a damn life, and when you have a contradiction like that, that's very political as well. What do I think? Do I agree with what I'm seeing or hearing? It becomes a comment. The dance becomes the opposite. The dance says, 'damn, I have a life!' Once you learn it then it's just learnt words, then you stop being so emotional about it, but one thing dance does, it communicates what words can't do.

This is a crucial moment, where Mat demonstrates how the student can shift her position, in this case an emotional response to discrimination which has been internalized, and so gain agency by using performance. The process here seems therapeutic but only as a means to an end. The dance-poetry becomes performance art as the student performs a selfeffacing parody through dance, thus shifting the parameters as to how she is 'read. The student finds her own aesthetic, which becomes a tool for responding to the discrimination that she experiences.

\section{Students as co-researchers and facilitators}

The co-researchers (as described earlier on in this chapter) identified a number of questions as a way into interrogating and scrutinizing the trajectory of the course, the tutor's pedagogical approaches in terms of relevancy and inclusivity, and the institution itself where the course was situated.

Each year a number of the students took on the role of co-researcher/ co-facilitator, meeting every few weeks to critically reflect upon the course and practice interview and facilitation techniques. These students became proactive investigators, evaluators, interviewers, facilitators and decision-makers, raising questions about the explicit and implicit learning opportunities within the course. The impact of 
this has led to the research model shifting from being an additional opportunity to becoming an integral and core part of the course, thus informing its ethos and philosophy.

These students took turns co-facilitating critically reflective discussions within the co-researchers' group and with the other students on the course, as well as interviewing the tutors. The journey that the co-researchers engaged in involved a process of re-positioning themselves as critical co-facilitators who questioned and interrogated the effectiveness, inclusiveness and relevance of the course. The co-researchers appeared to become more confident in articulating their reflections about their experiences of the course and what it raised for them. My reading of these conversations reminded me of Siebers' (2011) 'ideology of ability', and how he argues that this ideology has become the 'baseline by which humanness is determined, setting the measure of body and mind that gives or denies human status to individual persons' (Siebers, 2011: 8). These students appeared to be taking back what is rightfully theirs, and were moving into a position of clarity, self-advocacy and understanding of the potency of their own politicized performance and facilitation aesthetic. Rather than being passive receivers of yet another 'revolving-door project', students were defining how they wanted to use this course. The students as co-researchers and co-facilitators were able to decide upon the questions being asked in order to critique, inform and impact upon the course. But herein lies the contradiction: how was I to introduce the potential idea of the students as co-researchers and co-facilitators when they were sitting within the 'shadow of exploitation', as previously discussed?

\section{Introducing the co-researcher through Mantle of the Expert}

Early on in the course, and as an introduction to the role of the co-researchers, I facilitated a discussion with the group about their experiences as students with learning disabilities within a mainstream 
performing arts school, ${ }^{12}$ with the intention of gauging if they were able to critically articulate, express and share their experience within this institution. However, my attempts to initiate discussion were met with silence, and I felt an uncomfortable tension and unease within myself and with how I had clumsily presented my questions to the group. Outside of the workshop-studio and in the grounds of this institution, I had observed the stares that the students had experienced, but I did not feel in a position to name these moments for them. A few students began responding to my question: 'it's great being here'; 'I feel so lucky to be here' (25 January 2014). This was followed by more silence and I uncomfortably felt that perhaps my question had created the silence and closed down any responses other than positive confirmation that the students perhaps felt they had to give me. As an advocate of Mantle of the Expert (MoE) ${ }^{13}$ I felt it might be relevant to use this type of practice to create a dramatic frame where the students would be positioned as the experts in the room. I thought MoE might become a way for me to indirectly challenge the students' responses through role play in order to gain a more 'authentic' response. I explained the $\mathrm{MoE}$ technique and that I would re-enter the room in role as a visitor to the course, a potential new student.

I re-entered in role and quietly explained that I would like to join the group but was tentative at it being at a drama school. 'Do you have any advice for me? What is it like being on a course here?' I asked. Suddenly there was a buzz of activity, and the students offered their personal experiences, empathizing with my concern. Some of them spoke about meeting other students from other courses in the building:

Student E: It's like they are in their own zone ... You see other people doing their own stuff, and I'm like a window and I want to be like one of them ... this is when I feel very nervous ... will they actually like me?

Student D: We need to prove to them that we have the experience, the courage, the understanding, we need to say to them, we may be a little bit different but we are so like you. 
These comments led on to an enthusiastic discussion where most of the students shared examples of the challenges they experienced within an education environment that had been, historically, denied to them. The MoE role play ended and I was curious to return to Student E's comment, 'I'm like a window ... will they actually like me?' In response to this stimulus, the students then worked in small groups to create short performances in response to their 'nervous' experiences. They worked speedily and independently, creating pieces with the consistent theme of 'don't be scared of us - we are like you'. My reading of the performances was that the students had re-represented themselves as gentle-outsiders/the Other, not to be feared, trying to persuade these other students that they would not hurt or damage anyone. I felt overwhelmed as I watched how these students with learning disabilities performed and embodied the very fear that was constantly projected onto them. The students then engaged in a critically evaluative discussion about the performances, making reference to the similarity of their experience, and that the fear and discrimination that they all experienced was something that they had to endure on a daily basis in their individual lives.

Student F: I want to use performance to educate people about our learning difficulties and explain to them that although we are different, in many ways we are the same.

Student G: There are many similarities between us and everyone else, [and] we are still capable of doing stuff that everyone else does. Society needs to realize that.

The performance task was one of reclaiming place, where experiences could be shared and respected, and where the students could perform their own responses to how they are perceived by other students at the drama school and beyond. Perhaps the very act of performing these to one another allowed for a solidarity of experience, moving the group into a stronger position as they did not become vulnerable to any outsider. The students articulated their awareness of the politics of their presence within a drama school, and reflected on how they 
wanted to further use performance to shift institutional attitudes about disability. Following this MoE session, a core group of self-elected students became the co-researchers who met regularly, engaging in many reflective discussions about the course including this short but poignant exchange:

Student F: For me it's empowering because we have disabilities and people naturally put us into a box. But here there are normal people. So I feel empowered.

Students G: Most people think only normal people will go to this college. You may think that of me but I can do this.

Student $\mathrm{H}$ : It's giving them two fingers.

Student G: With the showbiz industry you're more noticed if you come here. ${ }^{14}$

There is an obvious and explicit division articulated in the above dialogue, between 'able' and disabled, 'them and us', and the privilege of being part of such an institution and the expectations of 'getting noticed. One of the students uses the phrase 'people naturally put us in a box ... here there are normal people ... So I feel empowered.' She demonstrates a sense of success in managing to exceed social discriminatory expectations and rules dictated to and placed upon her. Her choice of words to describe this is very visual, and she closes with a description of 'giving them two fingers', a slang and socially 'unacceptable' statement to those in authority. She is able to succinctly articulate her response to the imposed oppression that she has endured within the very place that historically and metaphorically has excluded her.

However, another question that perhaps needs to be considered is why this student places value on positioning herself within such institutions, and what is actually meant by this student's statement about 'being noticed. This is indeed a common belief amongst many performing arts students and graduates: that as long as they can 'fit in' then one day they will be 'noticed' by the 'gate-keepers' and ultimately succeed. If this ambition of 'being noticed' is not challenged, critiqued and problematized then these students will just continue to surrender 
any potential authority and autonomy. On the one hand this is troubling, but perhaps on the other hand, in order for these students to challenge the exclusion that they experience, they need to keep those 'gate-keepers' by their sides so that eventually they are able to reap the privileges denied to them. ${ }^{15}$

To apply this to the role of the co-researchers on the course, the students were interested in sharing their challenging experiences of being tutors and facilitators themselves, and wanted to explore why there were so few opportunities for such roles within the performing arts. The students felt that it was important to ensure that everyone understood the role and skills of such positions:

Student J: A facilitator is in a position of leadership, someone who makes it possible for others to do things, like care workers.

Student $\mathrm{H}$ : There are not many disabled teachers. I teach children with disabilities in the gym. If I ask to work with someone without disabilities, they say no. They see the wheelchair, not me.

Student J: I was an $\mathrm{LSA}^{16}$ in an $\mathrm{SEN}^{17}$ primary school for 4 years; I wasn't diagnosed with Asperger's at this point and maybe wouldn't have got the job if I had told them.

Student K: I teach people with disabilities to DJ. I like it when a facilitator breaks it down otherwise it's too much.

Student G: It was the teachers who said I couldn't do things. (13 February 2015)

These students demonstrate an eclectic experience and understanding of facilitation in a range of settings, whether as support workers and facilitators themselves or as students being facilitated. The overriding similarity in their responses is that due to experiences of how they are being 'read' as disabled people, they have received the message, directly or indirectly, that they cannot be part of mainstream society and that they should only work with other disabled people. Student G explained that if he had been labelled as learning-disabled before he gained his LSA position, he would not have been employed.

The only reason for these learning-disabled people coming together was their 'collective affinity' of experiences. Each of these individuals 
engage, articulates, creates, learns and facilitates in their own diverse way, which challenges any binary model of ability-disability. The idea of collective affinity is discussed and defined by Joan W. Scott:

Collective Affinities as playing on identifications that have been attributed to individuals by their societies and that have served to exclude them or subordinate them ... can be discussed in terms of disability politics, not because of any essential similarities among them, but because all have been labeled as disabled or sick and have faced discrimination as a result. (Scott in Kafer, 2013: 11)

The experience of discrimination, not the impairment, creates the collective affinity that brings these students together. Therefore, creating a space and a place for co-researchers to critique and share the impact of this discrimination enables an explicit sharing of this collective affinity. The act of doing this allows the student with learning disabilities to reposition herself or himself away from the institutionalized notion of disability which is based on a narrow binary of what she or he cannot do.

Student K: Will I get the respect I need?

Student L: I just want them to respect me as a facilitator and for the group to take part in all the activities. If they're talking and they are not paying attention, I'm worried what others might think of me or judge me.

Student G: I worry that some will say I'm being stupid. [on reflecting about their discussion] I didn't contribute because I was waiting for a break at the right time. I need to wait for a gap because I've been told to be quiet for so long - because it's less important. When I facilitate I criticize myself a lot and always tell myself I should have been louder.

Student R: Performing Arts is about playing to your strengths. If you have a weakness, turn it into strength.

Student K: A good facilitator breaks it down. Confidence is slowly building up due to the skills that I'm learning and the friendships I'm building helps me to overcome my fears. The voice workshops have helped. I've been bullied before about my voice. (6 March 2015) 
These fears may have little to do with impairment, and more to do with lack of confidence. For me, the course is not justifiable if it is only a performance-making course that does not address the issues of confidence and self esteem. In order to end the exclusion of people with learning disabilities, there needs to be a commitment to the creation of opportunities for these people to be the ones who do the imparting as critical facilitators and teachers. For example, the students criticized and blamed themselves for what they felt they lacked, as a number of students shared their dislike of their own voices. Student Z's response - 'I've been told to be quiet for so long' - indicates that she censors and edits herself so that she does not contribute. She also shared that her voice 'is too quiet to be heard anyway', which led to a discussion with the co-researchers about owning the space and adapting it in order to ensure that any 'difference' becomes a quality and an opportunity. The renowned drama educationalist Cecily O'Neill ${ }^{18}$ often talks with a whisper when she is facilitating and indeed the benefit of this is that she gains full focus from the participants, and a sense of urgency and intention is created. Another co-researcher suggested using a microphone, which everyone agreed would be a great idea and indeed would enable other participants to explore different ways of being heard and seen. The co-researchers demonstrated immense support, empathy and encouragement for one another as they tried to reclaim a positive diverse identity and became the critical voices of the course, so that whatever was being explored or created during the workshops could then be considered and critiqued. As Denzin states, performance ethnography 'must be political, moving people to action, reflection, or both, revealing agency' (Denzin, 2013: 13), and so rather than giving someone a voice for a brief moment, the action is documented, 'moving people to action', 'revealing agency', enabling the students to become the self-advocates.

This chapter has offered an insight into a new performing arts course for adults with learning disabilities within a higher education institution, arguing that for change to happen the complex politics of learning disability needs to be made more explicit within such courses 
and placed in the hands of those historically excluded. Examples of participative performance practices that aim to shift perceptions of disability through a disability arts aesthetic for political and social comment have been presented. The discussion has also articulated the role of the students as co-researchers and co-facilitators, as crucial agents in enabling change, inclusion and an inclusive pedagogical practice that can inform dominant ideologies of ability still current within higher education. The experiences and articulation by the students in this chapter calls for a revisitation of who can access Performing Arts courses and equally who can lead and facilitate such courses. As a way into challenging the accepted norms and rules of facilitation and inclusion, it might be useful to end on Zola's 'Crip Time' as a response to those 'ablest barriers ... [that] involve an awareness that disabled people might need more time to accomplish something or to arrive somewhere' (Zola in Kafer, 2013: 26). Crip Time can perhaps be used to understand and embrace disability rather than using it as a justification for exclusion:

It is this notion of flexibility ... that matters ... Crip time is flex time not just expanded but exploded; [it] requires reimagining our notions of what can and should happen in time or recognising how expectations of 'how long things take' are based on very particular minds and bodies ... [it is] a challenge to normative and normalizing expectations of pace and scheduling. (Kafer, 2013: 27)

Zola's Crip Time, placed at the centre of critical facilitation and participation, potentially offers a potent tool for challenging binary beliefs surrounding ability and disability. Rather than seeing disability as a barrier, Crip Time proposes an 'explosion' (ibid.) of stagnant values, and judgements that have been used to enshrine and justify the prevention of disabled people from gaining access to such skills and experiences. Instead, Crip Time insists on neuro-diversity, creativity and opportunity of engagement by those people with learning disabilities who have been silenced and excluded. 


\section{Acknowledgements}

I would like to acknowledge the following graduates who completed the course and whose voices and experiences are documented in this chapter: Cian Binchy, Tyson Bushe, Thomas Fryer, Housni Hassan (DJ), Rhea Heath (Creative Partner), Terrie-Louise Huggett, Zara Jayne-Arnold, Bethan Kendrick, Lily Patterson, Chaz Carmon Salter and Gary Turner. I am also indebted to Ciara Rose Brennan, Patrick Collier, Alex Covell, Mairi Hayes, Nick Llewellyn, Sally Mackey, Catherine McNamara, Sheila Preston and Verna Rhodes, and finally Simon Wood, Zennie and Isabella for their love and support. 
